\title{
Fortalecimiento de la Gestión del Capital de Trabajo mediante una Herramienta Tecnológica - Caso Empresarial Municipio de Girardot: Tienda Zuly y Ana María \\ Strengthening of Working Capital Management Through a Technological Tool - Business Case Municipality of Girardot: Tienda Zuly and Ana María
}

DOI: https://doi.org/10.17981/econcuc.42.1.2021.Econ.6

Artículo de investigación.

Fecha de recepción: 11/12/2019

Fecha de devolución: 10/11/2020

Fecha de aceptación: 17/12/2020

Fecha de publicación: 26/01/2021

Francia Elena Cruz Puentes (D) Universidad Piloto de Colombia S.A.M.

Girardot, Cundinamarca (Colombia) francia-cruz@unipiloto.edu.co

\section{Andrés Felipe Atehortua Leal iD \\ Universidad Piloto de Colombia S.A.M. \\ Girardot, Cundinamarca (Colombia) aatehortua20@upc.edu.co}

\section{Gabriel Enrique Gutiérrez Parra Universidad Piloto de Colombia S.A.M. Girardot, Cundinamarca (Colombia) gabriel-gutierrez@unipiloto.edu.co}

Para citar este artículo:

Cruz, F., Atehortua, A. \& Gutiérrez, G. (2021) Fortalecimiento de la Gestión del Capital de Trabajo mediante una Herramienta Tecnológica - Caso Empresarial Municipio de Girardot: Tienda Zuly y Ana María. Económicas CUC, 42(1), 93-121. DOI: https://doi.org/10.17981/econcuc.42.1.2021.Econ.6

\begin{abstract}
Resumen
En los últimos tiempos el estudio de comercio minorista ha adquirido auge, por tal motivo el presente artículo consistió en fortalecer la cadena de valor del sector tendero del municipio de Girardot, mediante una estrategia empresarial de gestión del capital de trabajo, que permitiera optimizar el movimiento de inventarios, clientes y cartera para administrar y orientar el efectivo para toma de decisiones de inversión. La metodología utilizada presenta un enfoque mixto, por cuanto combina características del enfoque cualitativo por la caracterización y descripción de la empresa caso de estudio para la identificación de las necesidades, y cuantitativo, ya que la investigación requirió de la implementación de mediciones numéricas. Los resultados permitieron optimizar la gestión del capital de trabajo, en lo que refiere a toma de decisiones, optimización en los informes presentados para los inventarios, cartera, efectivo. Se concluye que, al optimizar la gestión del capital de trabajo a través del uso de la herramienta, se mejora la capacidad de negociación con clientes y proveedores.

Palabras clave: Capital de trabajo; optimización; innovación; cadena de valor; sector tradicional; retail
\end{abstract}

\section{Abstract}

In recent times the study of retail trade has acquired a boom, for this reason this article consisted to strengthen the value chain of the grocery sector of the municipality of Girardot, through a business strategy of working capital management, which allowed to optimize the movement of inventories, clients and portfolio to manage and guide the cash for decision making investment. The methodology used presents a mixed approach, since it combines characteristics of the qualitative approach by the characterization and description of the case study company for the identification of needs, and quantitative, since the proposal for the development of the application requires the use of characters, codes and interfaces. The results allowed to optimize the management of working capital, in terms of decision making, optimization of the reports submitted for inventories, portfolio, cash. It is concluded that by optimizing the management of working capital through the use of the tool, the ability to negotiate with customers and suppliers is improved.

Keywords: Working capital; optimization; innovation; value chain; optimization; retail 


\section{INTRODUCCIÓN}

El estudio por el comercio minorista ha tenido un especial interés, de acuerdo a la revisión de antecedentes efectuada, en el cual se puede apreciar una amplia documentación por investigadores, trabajos de grado, e instituciones como FENALCO (Federación Nacional de Comerciantes) y Fenaltiendas (Programa Social de Apoyo al Tendero de Barrio), las cuales se orientan en la mayoría a estudios de caracterizaciones con respecto a este sector.

En ese orden de ideas, el presente artículo expone los resultados de la investigación Optimización de la cadena de valor del sector Tendero del Municipio de Girardot, mediante una herramienta de desarrollo Tecnológico adelantada por docentes y semilleros del Programa de Ingeniería Financiera, durante el año 2019, en el cual presenta inicialmente una caracterización del sector tendero de las prácticas relacionadas con la gestión de inventarios, cartera y efectivo, componentes del capital de trabajo, a partir de la aplicación de diversos instrumentos y de técnicas de indagación y observación directa de una empresa caso de estudio, sobre la cual se diseñaron unos indicadores financieros y de gestión, con el fin de medir la eficiencia de la herramienta de desarrollo tecnológico propuesta para la optimización.

\section{Revisión DE Antecedentes}

Desde el campo Nacional, FENALCO, ha liderado los estudios y resultados de las diferentes acciones que adelanta con sus asociados, desde el fortalecimiento, promoción y capacitación del sector. Particularmente para el año 2016 en su informe anual Económico y de Gestión, sobre el "Sector Nacional, grandes superficies y Almacenes de Cadena", presenta un informe detallado sobre el comercio minorista, además de presentar un análisis de tendencia de compra de productos por parte de los colombianos, el cual concluye que más de un 60\% de estos productos se compran a través del sector tradicional, cifra que supera a los almacenes de cadena y grandes superficies (FENALCO, 2016).

Para el año 2012 la Universidad del Norte, realizó un estudio cualitativo en seis ciudades de Colombia (Barranquilla, Cali, Medellín, Manizales, Valledupar y Neiva), denominado "Tiendas de Barrio en Colombia”. El estudio identificó 13 tipos de tiendas agrupadas en tres categorías en tiendas por apariencia, tiendas por su familiaridad, tiendas por su rol de alimentación. El estudio también establece características en cuanto a ubicación, disposición y facilidad para adquirir cualquier producto (Páramo, 2012).

Aunque muchos han augurado su total desaparición, se evidencia a partir de la tipología y categorización expuesta que ellas representan no solo una función comercial, sino también social, por los lazos que crean, lo que ha permitido mantenerse. Allí se realizan interacciones sociales, familiares, de amigos, de vecindad. 


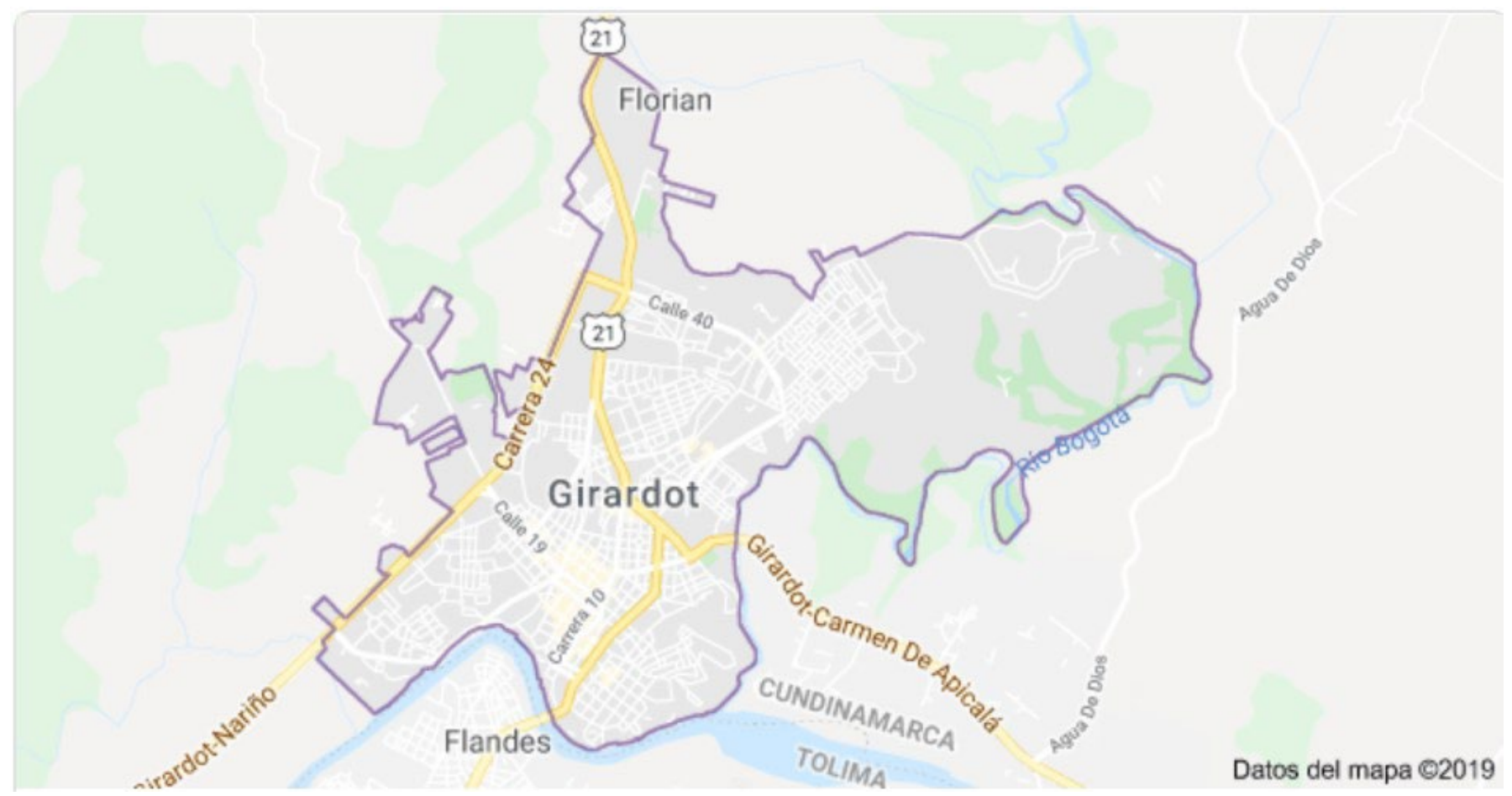

Figura 1. Mapa Municipio Girardot Cundinamarca. Fuente. Google Maps ${ }^{\odot}$.

Es decir, geográficamente como se muestra en la Figura 1, el municipio de Girardot se encuentra en una posición privilegiada, para satisfacer este tipo de comunidades. Esta actividad se ha convertido en un aporte para el crecimiento del municipio, además de la creación de valor y empleo, quienes a través de ventajas competitivas como el precio, la calidad, la ubicación, la variedad, formas de pago, presentación, servicio al cliente, familiaridad y además de ser un espacio para adquirir sus compras periódicas se ha convertido en un lugar de esparcimiento y encuentro con amigos, vecinos y familiares, lo que ha permitido que éstas se sostengan en el tiempo a pesar de la llegada de grandes superficies o nuevos conceptos de canales como son las tiendas Justo y Bueno, Ara, D1, entre otros.

Dentro de la revisión de antecedentes efectuada, se encontró una investigación de trabajo de grado, del Programa de Administración de Empresas de la Universidad Minuto de Dios. La investigación presenta también una caracterización, para lo cual elaboraron una encuesta aplicada por estudiantes del programa durante el año 2018 a 90 tiendas de Girardot, ubicadas en los barrios Buenos Aires, Esperanza, Alto de la Cruz, Miraflores, Vivisol, Kennedy y veredas como Barzalosa, y arrojó alguna información relacionada con aspectos socioeconómicos, e información en general (Tapiero, Montaña \& Sanchez, 2018).

Dentro de ella se evidenciaron algunos aspectos, relacionados con el control de mercancía o inventarios, aspectos de preferencia de establecimientos de los clientes, y desventajas que encuentran en el mercado. Otro hallazgo indica sobre la preferencia de los clientes por este tipo de establecimientos por factores como atención, artículos al menudeo y opciones de pago. Dentro de las desventajas se consideran la llegada de supermercados, y los nuevos formatos de tienda que se presentan. 
La Cámara de Comercio de Girardot, e Instituciones de Educación Superior (IES), como la Universidad de Cundinamarca, la Universidad Minuto de Dios, la Universidad Piloto de Colombia, y la Alcaldía de Girardot, adelantan actividades de capacitación, de promoción y desarrollo para diversos sectores económicos del municipio de Girardot, como es el sector tendero, con el fin de brindar herramientas en temas de facturación, modelo de negocios y de desarrollo empresarial.

A su vez la Universidad Piloto de Colombia en el año 2014, generó una investigación muy acuciosa a partir de un artículo de investigación en la cual generaron algunas alternativas para la población vulnerable de Girardot, siendo el sector Tendero una de ellas. Dentro de la investigación, Pérez y Ortiz, identifican una población de tenderos Recursos Naturales, los cuales catalogan como un grupo de personas que a través de la comercialización de los recursos naturales que produce el campesino, en sus parcelas, busca sus ingresos de subsistencia para su grupo familiar y sostenibilidad de su negocio (Peña \& Ortiz, 2014).

Los autores, afirman sobre el flagelo que vive este sector debido al mercado de usura quienes ofrecen tasas de interés con tasas de recuperación en el corto plazo. Además, sufren de los abusos del mayorista, el cual compra con un menor valor y lo vende a un valor más alto a los tenderos.

Otra población que identifican es el sector tiendas y negocios comerciales, los cuales definen como un grupo de personas que, a través de la comercialización de productos manufacturados, buscan lograr el mejoramiento de las condiciones de vida de su grupo familiar y la sostenibilidad de su negocio (Peña \& Ortiz, 2014).

Para este grupo los autores identifican algunas características como: "el 80\% de estos negocios funcionan por la intuición, que le coloca su propietario, pero no tienen una estructura propia de negocio que lo oriente hacia las perspectivas de un mercado competitivo" (Peña \& Ortiz, 2014, p. 93).

Dentro de las necesidades encontradas a partir de la metodología que los autores utilizaron están la falta de recursos financieros, la falta de asesoría financiera, falta de capacitación, falta de orientación en modelaje y montaje del negocio.

A su vez la investigación evidenció que el sector tendero, "con un 53\% muy significativo, este sector es bastante vulnerable ya que subsisten de lo que generan diariamente y algunos utilizan para la compra y reventa de estos productos dineros prestados a prestamistas" (Peña \& Ortiz, 2014, p. 94).

La Universidad de Cundinamarca también evidencia algunos aportes en este sector, con respecto a la caracterización de variables sociodemográficas.

Sin embargo y a pesar de los antecedentes de estudios e investigaciones presentados por diversas Instituciones de Educación Superior que sugieren más una caracterización socioeconómica del sector tradicional en Girardot, no se evidencian estudios recientes con respecto al impacto del ingreso al mercado local de grandes superficies o incluso del nuevo formato de comercio constituido por tiendas como Ara, Justo y Bueno o D1. Este hallazgo induce a la necesidad de fortalecer la gestión financiera del sector tendero desde las herramientas tecnológicas, en aras de poder competir y generar permanencia en un mercado cada vez más competitivo con tiendas que, aunque tengan este tipo de formato, han logrado penetrar en un mercado por su modelo de negocio como tiendas de conveniencia o tiendas de descuento. 


\section{Problemática}

\section{Caracterización del Sector Tendero}

El canal tradicional como se le conoce a las tiendas de barrio, ha sido parte de la historia económica, cultural y social en Colombia. Estas se han constituido no solo en un lugar para acceder de forma rápida a productos de la canasta familiar, sino también por encontrar opciones de productos en tamaños ajustados al presupuesto, realizar compras y emergencia de acuerdo al presupuesto diario que dispone una familia.

Las tiendas se caracterizan por ser una pequeña unidad de negocio familiar, dirigidas usualmente por su propietario, son de servicio rápido, permanecen abiertas prácticamente todos los días durante largas jornadas, se ubican muy cerca del hogar o lugar de trabajo, siendo más convenientes en cuestión de tiempo y precisamente a causa de su cercanía tienen un muy buen conocimiento de los clientes y manejan una muy buena relación, lo que les permite generar lazos de amistad y confianza derivada de la compra recurrente (Cámara de Comercio de Santa Rosa de Cabal, 2018).

Según un estudio realizado por Fenaltiendas y FENALCO, se estima que, en toda Colombia, hay 120 mil actores del pequeño comercio (tiendas de barrio), y cada año se van sumando más a esta industria; la edad promedio de los Tenderos es de 42 años; más de $55 \%$ de tenderos son mujeres y un $40 \%$ son cabeza de hogar; en cuanto a estudios realizados, el 31\% adelantaron su primaria; el 47\% son bachilleres; el 14\% tienen algún título técnico y el 8\% de tenderos son universitarios (FENALCO, 2018).

De otro lado, Servinformación indica que las tiendas de barrio representan el 22,2 por ciento de los 288.623 pequeños negocios que existen en 19 grandes ciudades y municipios del país. Sin embargo, a nivel nacional se estiman que son el $29.6 \%$, dado que se estiman en 720.000 los pequeños negocios y en 215.000 las tiendas (Lozano, 2017).

También se estima que entre el 63\% y el 65\% de las compras de alimentos, los colombianos las realizan a través de esa vía, por encima de los almacenes de cadena y grandes superficies.

Así mismo, Juan Ernesto Parra, director de Fenaltiendas, afirma que las tiendas de barrio comercializan el $52 \%$ de las categorías de los productos, y para canasta familiar pueden llegar a un 80\% (FENALCO, 2018).

FENALCO también afirma que las tiendas de barrios no solo aportan económicamente al país, sino que ayudan a disminuir el desempleo, ya que los establecimientos vinculan a 4,25 personas por cada uno. Esta vinculación favorece a las mujeres en un $63 \%$.

No obstante, y a pesar de los datos expuestos anteriormente, es evidente que durante los últimos ocho años la economía colombiana no ha presentado un comportamiento óptimo. Los datos refieren no solo a una desaceleración en Colombia, sino un efecto como consecuencia de la creciente incertidumbre de la economía mundial, con una caída de la demanda interna, que para el año 2016, fue la más baja durante ese período. Desde el año 2017, la economía colombiana viene pre- 
sentando una leve recuperación, gracias a los mejores precios de las materias primas y una mayor dinamización de la economía de Estados Unidos y de Japón (FENALCO, 2016).

Esta situación ha ocasionado una disminución en el consumo doméstico, componente mayoritario en el cálculo del PIB (Figura 2), provocado por el aumento sustancial de la inflación. FENALCO presentó un informe económico y de gestión para el año 2017, en el cual se asumían variaciones negativas para artículos de uso doméstico y de aseo personal, que no se registraban desde la crisis del año 2009. Otros productos que también registraron desaceleraciones fueron el grupo de alimentos y bebidas no alcohólicas, y otras mercancías de uso personal y doméstico (FENALCO, 2017).

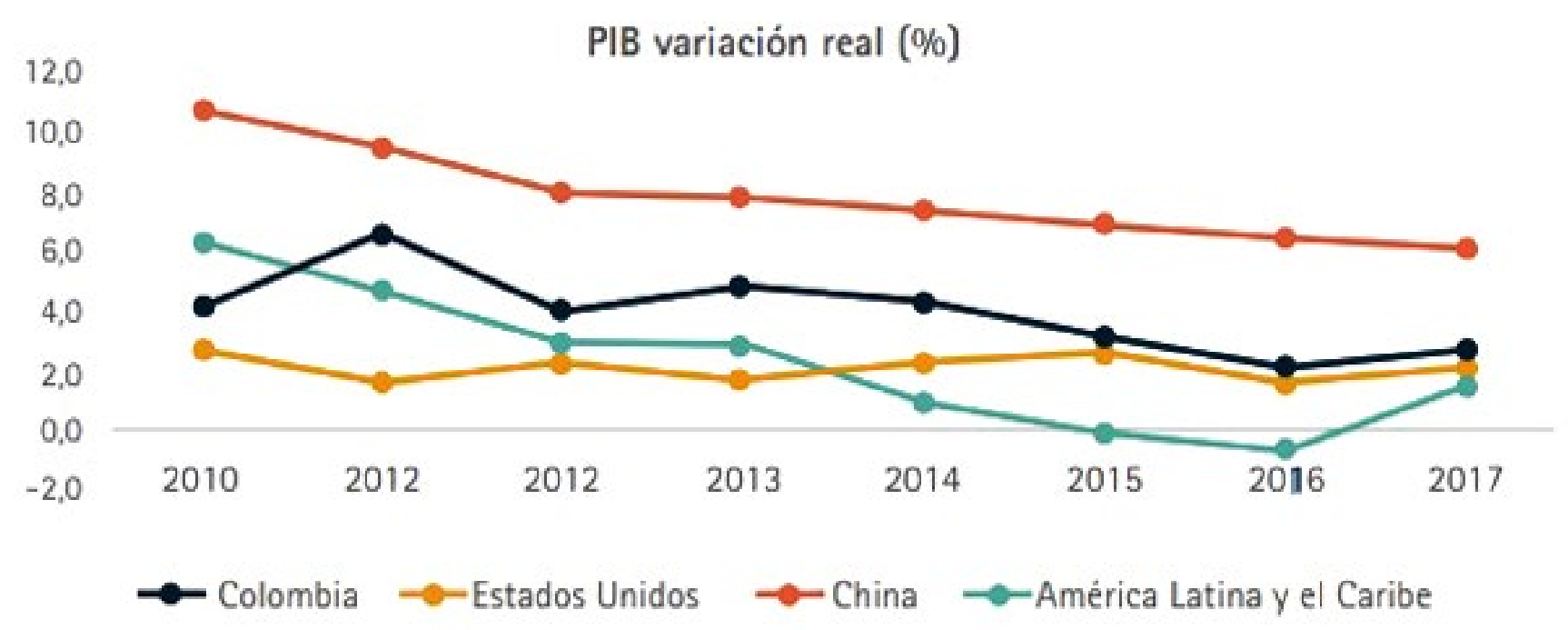

Figura 2. Variación PIB Real en Colombia. Fuente: Fondo Monetario Internacional (FMI, 2019).

Ahora bien, este panorama, presenta una realidad, y es que el contexto actual cambia permanentemente, y los negocios deben adaptarse rápidamente a él. Para el caso puntual del sector tendero en Colombia, el retail, permite que el usuario disfrute su proceso de compra, y en ello la oferta de servicios adicionales dentro de las tiendas es variada y los más valorados se encuentran entre las droguerías, cafeterías y bancos.

El informe de FENALCO presenta que dentro de la estrategia de crecimiento de retail en Colombia, el $71 \%$ de los usuarios afirma que su tienda tiene todo lo que necesita. Los factores más influyentes por categorías son el precio, el sabor, los beneficios para la salud, las ofertas o promociones y los ingredientes naturales.

Otro de los hallazgos encontrados en la investigación de Peña \& Ortiz (2014), es que el 87\% de los sectores vulnerables de Girardot, dentro de los cuales está el sector tendero, reciben ingresos mensuales de menos de $\$ 500.000$, lo que infiere que no cuentan con unos ingresos dignos para sobrevivir; el 73\% no genera sino un empleo y no posee otra fuente diferente de ingresos; y por último un dato común no solo para el municipio de Girardot, sino para la región del Alto Magdalena, los negocios comerciales, se encuentran representados en un $80 \%$ por este sector. 


\section{MÉTODO}

El grupo de investigadores teniendo en cuenta los antecedentes evidenciados de orden nacional y municipal con respecto al sector tendero aplicó un instrumento con el fin de recoger información de variables relacionadas con la gestión del capital de trabajo, como son el efectivo, la cartera y los inventarios, los cuales se consideran de gran importancia para garantizar un flujo frecuente que permita tomar de forma más acertada las decisiones con las cuales los tenderos se puedan enfrentar.

\section{Metodología}

Presenta un enfoque mixto, por cuanto combina elementos cuantitativos y cualitativos. El enfoque cualitativo utiliza la recolección de datos sin medición numérica para descubrir o afinar preguntas de investigación en el proceso de interpretación. (Hernández, Fernández \& Baptista, 2016). Para el enfoque cuantitativo, se requirió información relacionada con la aplicación de indicadores de gestión formulados por los investigadores, con el fin de medir el impacto de la implementación de la herramienta de desarrollo tecnológico, en sus actividades de efectivo, inventarios y cartera.

\section{Enfoque}

Parte de lo deductivo a lo inductivo. Inicialmente, se realiza un análisis general de cómo la empresa lleva a cabo su actividad de gestión de capital, para finalmente optimizar el tiempo de generación de reportes y por lo tanto tomar decisiones en aspectos financieros y administrativos, para ello tomando la base de datos aportada por la Cámara de Comercio de Girardot, la cual presenta un total de 9757 negocios inscritos, de acuerdo a su actividad y clasificados por su código CIIU.

El código con el cual se clasificó la población subjetiva fue el G4711 (Comercio al por menor en establecimientos no especializados con surtido compuesto principalmente por alimentos bebidas o tabaco), el cual representa el sector tendero y el total de la población que es igual a 1.387 tiendas formalizadas en la ciudad de Girardot.

\section{Muestra}

Arrojó un total de 67 negocios de tienda a entrevistar, para las cuales se generó un formulario de 15 preguntas, con los siguientes hallazgos: el 70\% de los negocios tienen más de seis años en el mercado; con respecto a la fijación de precios, casi el $65 \%$, establecen un porcentaje de ganancia asequible al consumidor, el rango promedio de ventas diarias, está entre 100.000 y $\$ 300.000$; más de un 50\% no hace uso de un método de inventarios.

El rango promedio del número de productos en estos establecimientos es 0 a 500; en la gran mayoría, los proveedores no les brindan plazos de pago (casi un 60\%); prima el uso de efectivo para el pago a sus proveedores; no financian su actividad 
ya que más de un $80 \%$ afirma que su medio son los recursos propios y no utilizan créditos en el sector formal, por su alto costo, lo cual dificulta el acceso; tan solo un $55 \%$ de los negocios encuestados afirma conocer sus ganancias; el número promedio de clientes a los cuales les otorga crédito está entre 5 y 10, cuyo monto aproximado es de $\$ 100.000$ mensuales; por último un $98 \%$ organiza sus cuentas por medio manual (cuadernillo).

\section{Grupo Focal}

Se realizó con doce tenderos del municipio de Girardot, en el cual se identifica que, en cuanto a la gestión de efectivo, los tenderos llevan su control de forma manual, no tienen claridad en el monto real de entradas diarias, no utilizan mecanismos de ahorro a través de productos financieros, y no realizan planeación sobre las inversiones y posibles fuentes de financiación ya que desconocen cuáles son sus utilidades al finalizar el periodo.

Por otro lado, en la gestión de inventarios, los tenderos manifiestan no tener conocimiento del número exacto de sus cantidades de inventarios, no conocen cual es la rotación de su inventario, no manejan un stock ni métricas sobre los productos, no logran identificar los productos de más baja rotación y no cuentan con un control de productos vencidos. Por último, se identifica que los tenderos se niegan a la opción de ofrecer crédito ya que no tienen las herramientas necesarias que les permita controlar los clientes que manejan sumado a que han tenido malas experiencias con personas que les han quedado adeudando sumas altas los cuales le han afectado su capital de trabajo.

Los hallazgos presentados anteriormente, evidencian en primer lugar una falta de atención permanente de este sector por parte de las entidades municipales, además la necesidad de generar estudios serios que permitan establecer alternativas, medios y recursos para obtener ingresos para estos establecimientos de acuerdo a sus necesidades, facilitar el mejoramiento de la calidad de vida, aumentar las posibilidades de acceso al crédito formal, incrementar sus niveles de venta, y poder de negociación con sus proveedores, implementar procesos de innovación que optimicen la gestión del capital de trabajo, y con esto mejorar las decisiones que se tomen al interior del establecimiento.

\section{Constructo Teórico}

\section{Cadena de Valor}

La Comisión Económica para América Latina, propone una metodología para el fortalecimiento de las cadenas de valor, mediante el diseño de estrategias participativas a nivel de actores que participan en la cadena.

Su metodología busca la resolución de cuellos de botella, mediante a la articulación de los actores que permitan un escalamiento económico y social. Para ello la innovación es un elemento esencial del escalonamiento entendida en un sentido amplio y flexible (Comisión Económica para América Latina-CEPAL, 2016). 
La CEPAL busca a partir de esta metodología, cambios profundos en la estructura productiva, lo cual resulta de la interrelación de dos fuerzas. La primera es la innovación que implica desaprender y aprender lo necesario para responder y sacar provecho de las oportunidades del mercado. Esta fuerza debe estar en relación de generar cambios y valor agregado en otras actividades complementarias (CEPAL, 2013).

Cabe recordar que siendo la presente investigación una segunda fase del eje de Encadenamiento Productivo y Asociatividad Estratégica del MAIIP, toma en cuenta ahora para este eslabón de la cadena, una vez se analiza y se fortalecen las actividades operativas de una empresa caso de estudio T\&T, el sector tendero como el cliente final, y vincula la participación de aliados como es la Cámara de Comercio de Girardot, quien permite aportar la base de datos de los tenderos formales, para realizar un grupo focal que permitiera corroborar la actividades relacionadas con la gestión del efectivo, la cartera y los inventarios.

Ahora bien entendiendo que la cadena de valor comprende la amplia variedad de actividades requeridas para que un producto o servicio transite a través de diferentes etapas, desde su concepción hasta su entrega a los consumidores y la disposición final de uso (Kaplinsky \& Morris, 2009), los investigadores consideraron pertinentes esta investigación teniendo en cuenta no solo lo que representa este canal tradicional para la economía Girardoteña, sin que también se convierte en un medio de subsistencia para muchas familias del municipio y la región.

Como se mencionó anteriormente, esta metodología considera el escalamiento económico y social. Desde el escalamiento económico, existen cuatro formas: escalamiento de productos, Escalamiento de procesos, escalamiento funcional, escalamiento de cadena. Para el caso puntual de esta investigación el escalamiento de procesos se convierte en la forma en la cual, a partir de la vinculación de tecnología, permite este fortalecimiento.

La metodología toma en cuenta 9 pasos, los cuales se presentan en la Figura 3:

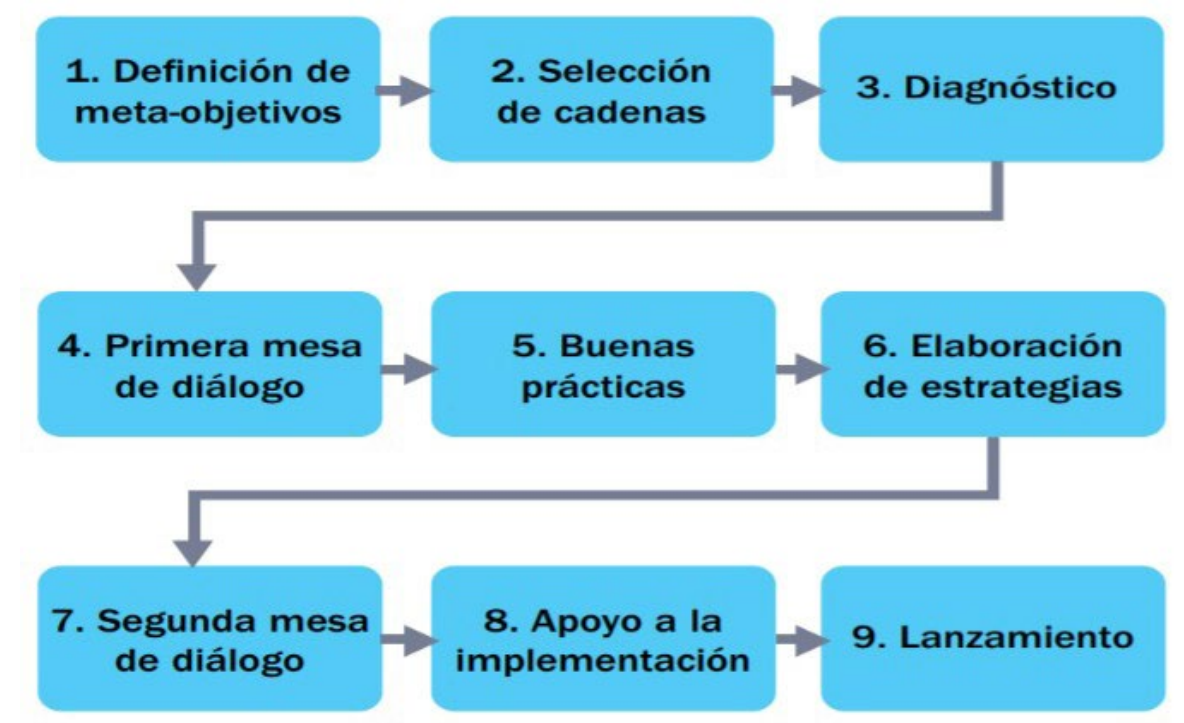

Figura 3. Pasos Metodología Fortalecimiento Cadena de Valor CEPAL. Fuente: CEPAL (2016). 
Ahora bien, la metodología básicamente contempla la identificación de cuellos de botella, y se diseñan estrategias participativas, se establecen mesas de diálogo para validar los resultados obtenidos en el diagnóstico, y favorecer la construcción de acuerdos, y por último se transfieren conocimientos (CEPAL, 2017).

La Cámara de Comercio, siendo aliado de la presente investigación, permite esta metodología participativa al brindar los espacios de diálogo con mesas de trabajo y grupos focales de un número determinado de participantes del sector tendero.

Esta fase fue fundamental, con el fin de seleccionar la empresa caso de estudio sobre la cual se estructuró el prototipo de la herramienta tecnológica para hacer gestión del trabajo, sobre el cual se evidenció la necesidad inicialmente.

Por otro lado, el enfoque de orientar alternativas de solución para fortalecer la capacidad productiva de una economía desde las cadenas de valor no es nuevo. Desde la década de los años 80, se establecieron los primeros fundamentos, teniendo en cuenta la necesidad de contar con una visión amplia para generar el fortalecimiento, que permitiera robustecer las actividades de los eslabones de la cadena y poder hacer frente a las necesidades, oportunidades y retos del contexto económico derivado de las diferentes crisis.

Teniendo en cuenta también el carácter de esta metodología, sobre la igualdad en el ámbito remunerado, se seleccionó esta empresa caso de estudio, por los rasgos del propietario del sector tradicional, ya que es mujer madre de cabeza, y su actividad la desarrolla con el fin de obtener ingresos para sostener su núcleo familiar, compuesto por sus hijas y por sus padres.

\section{Capital de Trabajo}

El capital de trabajo se reconoce como la diferencia entre la inversión y la financiación que realiza la empresa al corto plazo, coincidiendo con (Gitman \& Zutter, 2012), quienes plantean que "el capital de trabajo neto se define como la diferencia entre los activos corrientes de la empresa y sus pasivos corrientes" (p. 544). Su gestión es de vital importancia ya que permite a las empresas poder mantener los niveles adecuados de liquidez y responder oportunamente a los pagos u obligaciones adquiridas a corto plazo para el desarrollo de su actividad.

Gestionar eficientemente el capital de trabajo permite a las empresas en este caso de estudio comerciales del sector tendero mejorar en la utilización de sus recursos, ser más agiles en la realización de sus procesos y lograr mejorar sus resultados; Así mismo, crea valor para los clientes al mantener un adecuado control sobre los artículos y en algunos casos lograr acceder a promociones cuando sea necesario rotar rápidamente algún producto.

\section{Indicadores de Gestión}

Los indicadores de gestión permiten medir el desempeño de los procesos de una empresa, cuyo resultado pueda ser comparado con algún dato de referencia, el cual señale las variaciones o los comportamientos de dichos indicadores, para luego tomar 
las medidas necesarias de corrección o la prevención según sea el caso. Además, se debe establecer un sistema determinado para el análisis y la comprensión de la acción o hecho que me cause tal desviación con el objetivo de mejorar los resultados de los procesos que contraigan problemas. En otras palabras, son un instrumento de gestión que refleja la realidad de los procesos internos de una empresa y que también da soporte a la toma de decisiones.

Es la mejor forma de conocer y mejorar la marcha de una empresa, contando con los beneficios de controlar y manejar la evolución o el estancamiento de una compañía, de un departamento o de un área en particular. No realizar una gestión correcta contrae un aumento en los costos y una poca capacidad de competitividad. Por tal motivo es muy importante medir los procesos, ya que cada día la competencia aumenta, las empresas y los negocios están ligados a constantes cambios y se ven en la necesidad de tener claro la forma de como analizar y evaluar los procesos de su negocio, es decir deben conocer plenamente su sistema de medición de desempeño.

\section{DesarRollo y ANÁLisis}

Ahora bien, conjunto a la gestión del capital de trabajo es importante analizar las actividades primarias desarrolladas por los tenderos a través de la revisión de su cadena de valor del sector, con el fin de analizar los indicadores de gestión para así mismo tomar decisiones que conlleven a la optimización de sus recursos, procedimientos y facilite la administración del negocio.

Lo anterior debido a que, es clave a la hora de potencializar la actividad económica y aumentar la competitividad, además de redefinir los procesos que hacen parte de la cadena de valor para aumentar su eficiencia, mediante el uso de la tecnología y la innovación en el desarrollo de las actividades operativas y gerenciales.

Una vez se identifican estas necesidades se procede a través de la empresa caso de estudio a evaluar su cadena de valor. los procesos que desarrolla internamente para poder entregar los productos que comercializa a los clientes.

Para ello se realizan diversas visitas de reconocimiento y caracterización donde se identifican los procesos de pedido, almacenamiento, venta o despacho, arqueo, cobros y pagos, los cuales, de acuerdo con la logística interna, servicio y venta, abarcan la gestión financiera del manejo de inventarios, manejo de proveedores, manejo de crédito, control de ventas y efectivo. Tal y como se presenta en la gráfica No 3 , cada una de las actividades que hacen parte de la gestión de capital de trabajo en cualquier organización.

Así mismo se logra identificar que los procesos de apoyo que hacen parte de la cadena de valor (Figura 4) son abastecimiento entendido como los despachos que realizan los proveedores, recurso humano la cual hace referencia al personal que tiene en ventas el tendero. Cabe resaltar que en la mayoría de los casos se identifica que los familiares son las primeras personas que realizan este soporte e infraestructura donde se encuentra la reposición y compra de los activos locativos como stands, congeladores, etc. 


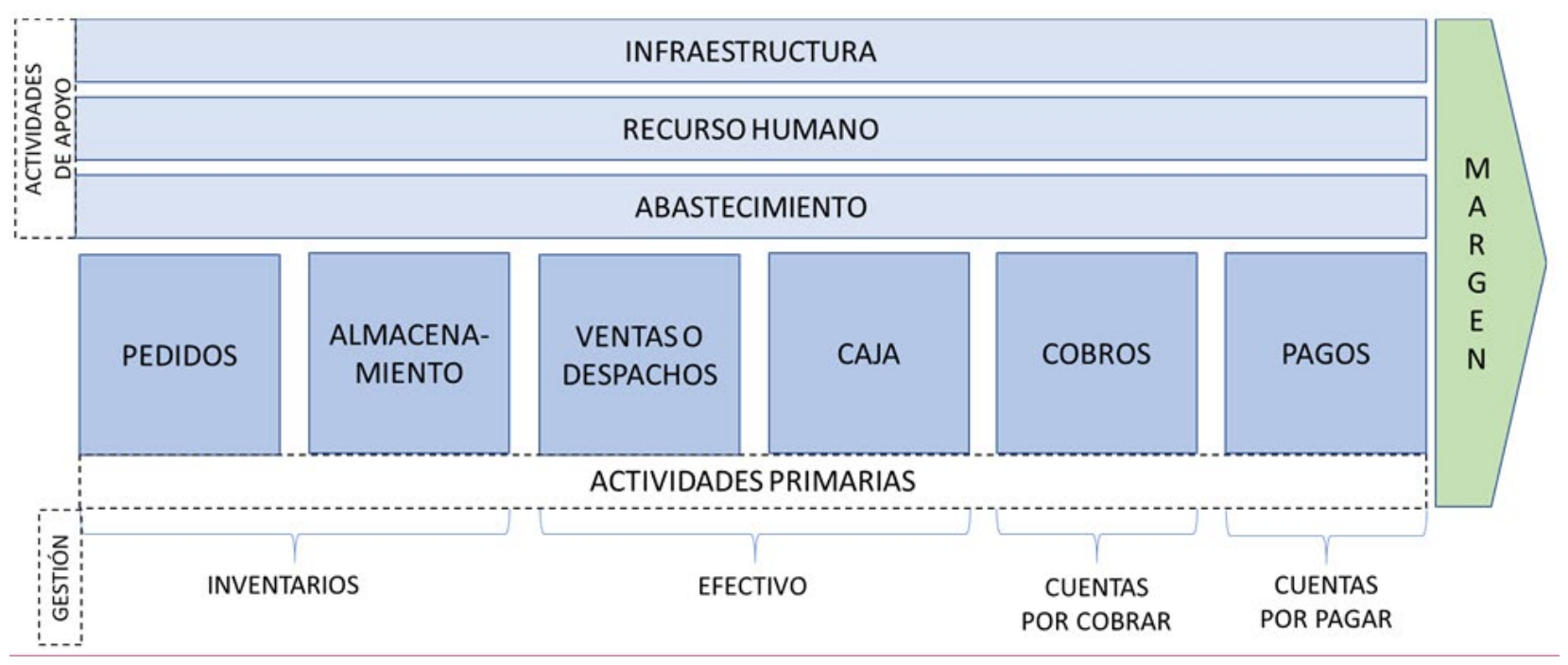

Figura 4. Cadena de Valor del Sector Tendero asociada a la gestión financiera del capital de trabajo. Fuente: Elaborada a partir de Porter (2009).

\section{Analogía indicadora de gestión y financiera en la cadena de valor}

Una vez identificados los procesos primarios y de apoyo existentes en la cadena de valor, se evalúa la gestión del capital de trabajo por medio de los indicadores de gestión y financieros, concentrándonos en los primarios ya que son las actividades que tienen total dependencia con las decisiones que puede tomar el tendero.

El proceso pedido está relacionado con la gestión de inventarios y hace referencia a las actividades que hace el tendero para solicitar productos a sus proveedores en el cual se involucran los procedimientos de conteo de inventario, identificación de faltantes y registro de unidades a solicitar. A continuación, se relacionan los indicadores faltantes de inventario y rotación de inventarios analizados en este proceso.

\section{Indicador de Gestión: Faltantes de Inventario}

Mide el tiempo que se demora el tendero verificando los faltantes de inventario, su resultado se expresa en función de tiempo (ecuación 1).

$$
\begin{gathered}
\text { Tiempo en verificar el registro del inventario } \\
+ \text { tiempo de reconteo }
\end{gathered}
$$

Como resultado se muestra que, el tiempo utilizado por el tendero para identificar el faltante de cualquier clase producto sumado al conteo del inventario es de 4 minutos 23 segundos esto a causa de no tener el debido registro del inventario; esto puede generar pérdidas en el inventario y disminución de utilidades a finalizar los periodos. Adicional que expone el negocio a tener faltantes producidos por robos. 


\section{Indicador Financiero: Rotación de inventario}

Representa el número de días que en promedio transcurren desde la compra de los productos y la venta de estos. Cabe resaltar que entre más bajo sea este indicador más frecuente son los ciclos de transacción y esto representa mayor flujo para el negocio. En este caso es importante contar con un adecuado control sobre el mismo ya que al no identificar rápidamente los productos de mayor rotación se podría incurrir en faltantes de inventario que podría generar disminución de ventas (ecuación 2).

$$
\frac{\text { Inventario promedio } \times 360}{\text { Costo de Venta }}
$$

La tienda demora en promedio 101 días, en convertir su inventario en efectivo, en otras palabras, en venderlo; las causas que se asocian a este elevada cifra es no existe un control adecuado sobre la rotación de cada producto, se carece de base de datos; lo cual es preocupante ya que no solo se puede generar pérdida de clientes sino también de productos ya que la mayoría de los productos son perecederos y al no venderlos antes de su fecha de vencimiento ocasionan que se asuman perdidas.

El siguiente eslabón de la cadena es el proceso de almacenamiento el cual reúne los procedimientos y actividades que realiza el tendero para custodiar y conservar sus productos en condiciones óptimas para su venta desde que son compradas hasta que son requeridos por el cliente. Aquí los procedimientos que podemos identificar son recepción de mercancía y registro de inventario. El indicador que se usó para medir el proceso son registro de productos.

\section{Indicador de gestión: Registro de productos}

Mide el tiempo en registrar un producto de acuerdo con la cantidad total de inventarios (ecuación 3).

Total de tiempo que se demora registrando los productos

Total del Inventario

Al calcular este indicador se identifica que, en promedio tarda en registrar un producto es de 10 segundos esto debido a que el momento de realizar el registro lo hace de forma manual de manera lenta y lo cual puede ocasionar errores en el registro al estipular cantidades incorrectas.

En el proceso de ventas y/o despacho se encuentran las actividades relacionadas con entrega de productos, facturación y registro de ventas. En este proceso la tienda realiza la recuperación de lo invertido en inventario y genera el flujo para realizar la compra nuevamente de los productos. En este caso se utilizaron los siguientes indicadores entrega de cambio, devolución de productos y ciclo de caja para medir el proceso. 


\section{Indicador de gestión: Entrega de cambio}

Mide el tiempo que se está utilizando en el negocio para la entrega del cambio, por el pago de uno o varios productos, según la cantidad total de clientes atendidos (ecuación 4).

Total tiempo que se demora entregando el cambio

Total Clientes atendidos

(4)

El tiempo que se demora entregando el cambio por es de 9 segundos en promedio, un tiempo bastante largo debido a que las cuentas se realizan de forma mental o se escriben en un papel. ocasionando demora en el tiempo que se utiliza en atención al cliente.

\section{Indicador de gestión: Devolución de productos}

Permite conocer del total de inventarios que porcentaje está siendo devuelto por los clientes (ecuación 5).

$$
\frac{\text { Total de productos devueltos }}{\text { Total del Inventario }} \times 100
$$

Tomando como muestra un inventario de 20 productos se identificó que en promedio en la tienda los clientes están devolviendo 1 producto, lo cual corresponde al $5 \%$ del inventario. Esto generalmente sucede por desconocimiento y no control de las fechas de vencimiento que tiene cada producto; Además no hay un registro para verificar y comparar estas fechas. Esto genera pérdidas ya que, si no se devuelve el producto en el tiempo establecido por el proveedor, no se podrá hacer el cambio y la tienda debe asumir el valor del producto.

\section{Indicador financiero: Ciclo de caja}

Mide el tiempo que pasa desde el momento en que se efectúan las salidas de efectivo por la compra de los productos, la venta y el tiempo de la recuperación de cartera, a este tiempo se resta el tiempo que en promedio está tardando la tienda en pagar sus obligaciones (ecuación 6).

$$
\text { Ciclo Operacional - Ciclo de pago }
$$

Como el ciclo operacional es mayor al ciclo de pago dando como resultado 17 días se evidencia que la tienda tiene problemas en la gestión de su efectivo a causa de una alta rotación de inventarios, provocada por el descontrol que tiene al no identificar los productos que menor rotación tiene. Así mismo, los pagos que efectúa la tienda 
tienen plazos muy cortos, lo cual desencadena problemas de liquidez, afectando la recompra de productos y la actividad normal de negocio.

En cuanto al proceso de caja se identifican las actividades que hacen parte en el reporte de ventas diarias y el cuadre entre ingresos y salidas en el día. Identificar las ventas diarias y mantener un control de estas le permite al comerciante evidenciar cuando hay una disminución de estas y en este caso poder tomar medidas como promociones y rebajas las cuales le permitan nivelar los niveles de ventas así esto traiga una reducción en su margen de contribución. Al final lo importante es lograr un sostenimiento en la actividad comercial que permita cumplir con las obligaciones y la compra de los productos. Se toman los indicadores de cuadre de caja y capital de trabajo para medir el proceso.

\section{Indicador de gestión: Arqueo de Caja}

Mide el tiempo transcurrido contando el efectivo de su empresa en un momento determinado (ecuación 7).

Conteo del tiempo que se demora en el Arqueo de Caja

El tiempo promedio que demora el arqueo en la tienda es de 6 minutos 1 segundo Esto debido a que el conteo se realiza de forma mental y se utilizan elementos arcaicos como calculadora, al llevar a cabo este proceso así, se puede ocasionar errores humanos los cuales son más propensos en estos casos, adicional, es muy difícil poder identificar descuadres en la caja.

\section{Indicador financiero: KTNO (Capital de Trabajo Neto Operativo)}

Es un indicador financiero que expresa la cantidad de efectivo que tiene empresa para cumplir con su operación y generar nuevas inversiones (ecuación 8).

$$
\text { Cuentas por cobrar + Inventarios - Cuentas por Pagar }
$$

El negocio cuenta con $\$ 604.000$ para operar la tienda o generar reinversión, El manejar un capital de trabajo optimo le permite responder a los pagos imprevistos que se puedan presentar, así mismo se pueden aprovechar oportunidades en la compra de nuevos productos o promociones ofrecidas. Desde el punto de vista gerencial, mantener un capital de trabajo bajo pero adecuado permite controlar eficientemente las obligaciones a corto plazo y mantener una imagen favorable ante proveedores y empleados lo cual permite al acceso a plazos para la financiación y la baja rotación del personal.

El proceso de cobro hace referencia a la gestión que adelanta el negocio en su cobranza, en el otorgamiento del cupo de crédito, las actividades que desarrolla para la recuperación de esta y la frecuencia con la que pagan los clientes. En este caso 
se toman como indicadores la totalización de cuentas por cobrar y la rotación de cuentas por cobrar.

\section{Indicador de gestión: Totalizar-cuentas por cobrar por cliente}

Mide el tiempo que se demora en totalizar las cuentas individuales, de acuerdo con la cantidad de cliente que se le vende a crédito dentro del negocio (ecuación 9).

Tiempo que se demora totalizando las cuentas por cobrar a clientes

Cantidad de Clientes
(9)

El tiempo que en promedio tarda el tendero en sacar la cuenta de un cliente es de un minuto dos segundos, las causas de este excesivo tiempo usado es que los registros son manuales lo que operativamente ocasiona demora en encontrar las cuentas, sumar y totalizar las mismas. Adicional esto impide al tendero poder controlar las fechas de pago ocasionando problemas por la baja rotación de la cartera.

\section{Indicador financiero: Rotación de Cuentas por Cobrar}

Este indicador establece los días que se demora una empresa en cobrar la cartera al cliente (ecuación 10).

$\frac{\text { Cuentas por cobrar } \times 360}{\text { Ventas }}$

En el caso de la tienda, cada 54 días recupera o convierte las cuentas por cobrar en efectivo, para poder disminuir estos días normalmente el dueño debe acudir a gastos adicionales como visitas o llamadas de cobro, el hecho que se maneje un número tan alto trae como consecuencias imposibilidad para cumplir sus pagos.

El último proceso es pagos, el cual hace referencia a las actividades desarrolladas para el cumplimiento de las obligaciones con proveedores, financieras y con empleados. En este caso medimos la relación que tarda el tendero tanto en realizar los pagos como en efectuar la recepción del pedido.

\section{Indicador de gestión: Pedido a Proveedores}

Mide el tiempo que demora realizando el pedido respectivo por producto a sus proveedores según su cantidad total (ecuación 11). 
Se identifica que, el tiempo que se utiliza para realizar el pedido es de un minuto cinco segundo debido a que no se cuentan con mecanismos que faciliten los pedidos, haciendo que estos se realicen incluso con base a la experiencia y la revisión rápida del inventario de forma visual.

\section{Indicador financiero: Rotación de Cuentas por pagar}

Este indicador permite conocer los días que se demora la empresa por cumplir sus obligaciones o pagar a terceros (ecuación 12).

$\frac{\text { Cuentas Por Pagar x } 360}{\text { Costo de Venta }}$

La empresa caso de estudio tarda 138 días en promedio en pagar sus obligaciones según el indicador, esto no representa un buen proceso porque genera mala imagen ante las entidades financieras y proveedores, adicional que se pueden estar perdiendo oportunidad de ahorro por pagos anticipados o acceso a promociones que tenga el proveedor.

En resumen, a continuación, la Tabla 1 muestra los indicadores de gestión y financieros analizados por cada proceso de la cadena de valor asociados al capital de trabajo los cuales nos muestra un panorama poco alentador, que es evidentemente la situación operativa y financiera por la que atraviesan las tiendas de barrio.

TABLA 1.

Indicadores de gestión y financieros por proceso en cadena de valor.

\begin{tabular}{|c|c|c|c|c|c|}
\hline \multirow{2}{*}{$\begin{array}{c}\text { Variable } \\
\text { Capital de } \\
\text { Trabajo }\end{array}$} & \multirow{2}{*}{$\begin{array}{c}\text { Proceso en } \\
\text { Cadena de Valor }\end{array}$} & \multicolumn{2}{|c|}{ Indicador de Gestión } & \multicolumn{2}{|c|}{ Indicador Financiero } \\
\hline & & Indicador & $\begin{array}{c}\text { Resultado } \\
\text { Actual }\end{array}$ & Indicador & $\begin{array}{c}\text { Resultado } \\
\text { Actual }\end{array}$ \\
\hline \multirow{2}{*}{ Inventarios } & Pedido & Faltantes de Inventario & $4 ’ 233^{\prime}$ & \multirow{2}{*}{$\begin{array}{l}\text { Rotación de } \\
\text { inventario }\end{array}$} & \multirow{2}{*}{101} \\
\hline & Almacenamiento & Registro de productos & $10 ”$ & & \\
\hline \multirow{3}{*}{ Efectivo } & \multirow[b]{2}{*}{$\begin{array}{l}\text { Ventas y/o } \\
\text { despacho }\end{array}$} & Entrega de cambio & $9 "$ & \multirow[b]{2}{*}{ Ciclo de caja. } & \multirow[b]{2}{*}{17} \\
\hline & & $\begin{array}{l}\text { Devolución de } \\
\text { productos }\end{array}$ & $5 \%$ & & \\
\hline & Caja & Arqueo de Caja & 6’01” & KTNO & $\$ 604.000$ \\
\hline $\begin{array}{l}\text { Cuentas por } \\
\text { cobrar }\end{array}$ & Cobro & totalizar cxc por cliente & $1 ” 02 ”$ & Rotación de CXC & 54 \\
\hline $\begin{array}{l}\text { Cuentas por } \\
\text { pagar }\end{array}$ & Pago & Pedido a Proveedores & $1 ” 05 ”$ & Rotación de CXP & 138 \\
\hline
\end{tabular}

Fuente: Elaboración propia.

De este modo, se realizó un aporte significativo para poder optimizar los procesos que hacen parte de la cadena de valor del sector tendero en la empresa caso 
de estudio, donde a través de una herramienta de innovación financiera se logró mejorar cada uno de estos indicadores permitiendo así acortar el tiempo en la realización de las actividades operativas y mejorar las actividades de venta, cobro y pago.

Dicha herramienta se engloba dentro del área de diseño y desarrollo de las TIC, la cual permite atender las necesidades del sector tendero, y fue diseñada y desarrollada en el entorno de programación de Microsoft VBA (Visual Basic for Applications) versión 2019, el cual es un lenguaje de programación de macros, siendo ésta una serie de líneas de código cuyo objetivo principal consiste en almacenar instrucciones dentro de un archivo Excel que posteriormente se podrán ejecutar cuando el usuario lo requiera.

\section{Principales funciones de la herramienta}

El desarrollo de esta herramienta permite al tendero:

- Generación de facturas con código de referencia automático: Alerta por cantidades existentes, registro por venta débito o crédito, ingreso de artículos por nombre o código, suprimir artículos, totalización de la venta, ingreso y cálculo del cambio a entregar.

- Consulta de facturas históricas, diarias, semanales y mensuales: Consulta por factura, totalización de ventas, consulta, ingreso y modificación de nuevos productos (existencias, entradas y salidas), ingreso por categoría, costo, precio, totalización de inventario, consulta por producto, manejo de stock.

- Consulta, ingreso y modificación de CXC: Ingreso de datos personales, consulta por cliente, totalización de CXC.

- Consulta, ingreso y modificación de Gastos: Ingreso por tipo de gasto, consulta de gatos mensuales, totalización de gastos.

- Consulta, ingreso y modificación de Proveedores: Ingreso de proveedores, compras enlazadas para la automatización del inventario, consulta por proveedor.

- Reportes: Resumen por rango de fechas, visualización de ventas por tipo de producto, producto más vendido, margen de contribución, utilidad.

- Seguridad: Protección al acceso de la información, copias de seguridad, desactivación del entorno de desarrollo.

\section{Interfaz amigable e intuitiva}

Uno de los pilares fundamentales de la herramienta es seguir una línea de diseño amigable e intuitiva (Figura 5) para cualquier persona que vaya a manipular la herramienta, que por medio de iconos representativos de las funcionalidades permitan a la persona manipularlo con fluidez, como se presenta a continuación: 


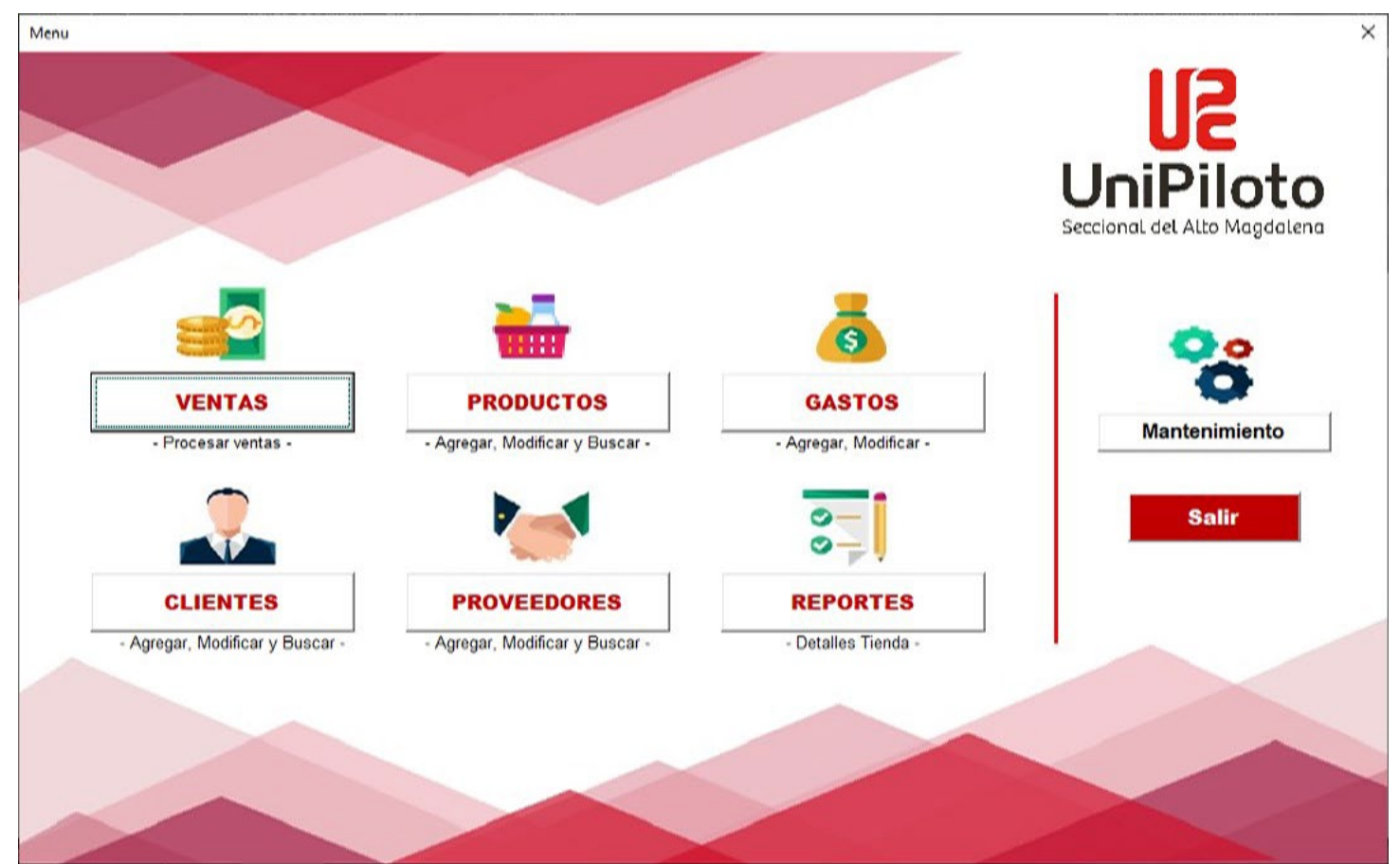

Figura 5. Interfaz herramienta de gestión de capital de trabajo tenderos. Fuente: Elaboración propia a partir de VBA (2019).

\section{Login a través de un usuario y una contraseña previamente asignada}

Para la limitación de acceso a la herramienta, se establecerá un usuario asignado y personalizado por microempresario de barrio para que el acceso a esta esté estrictamente limitado para la manipulación de la herramienta, con el fin de minimizar riesgos de alteración, pérdida o incoherencia de la información que esta procesa, como se muestra en la Figura 6.

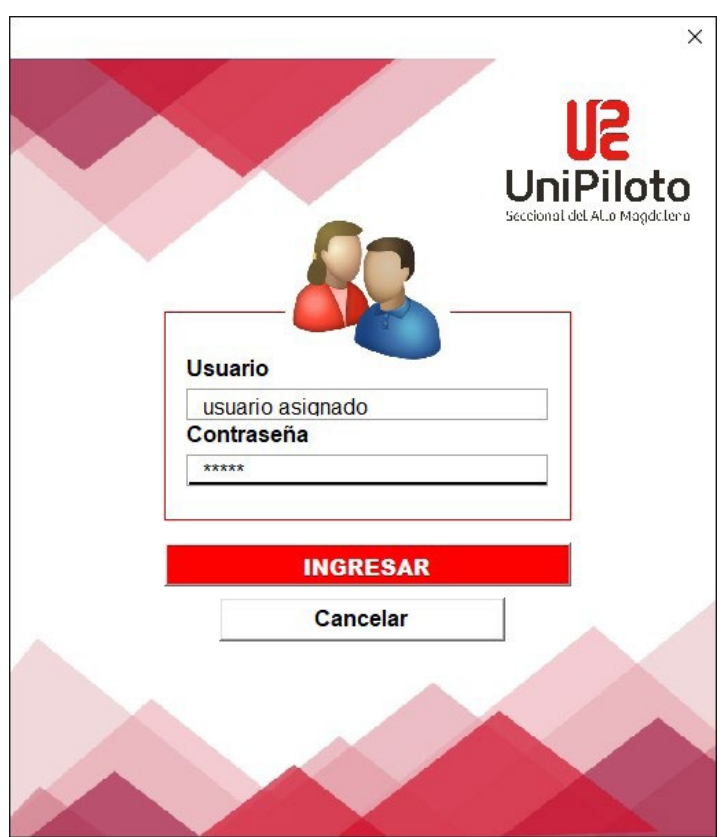

Figura 6. Acceso a la herramienta.

Fuente: Elaboración propia a partir de VBA (2019). 


\section{Generación de facturas con código de referencia automático}

La herramienta permite generar facturas de una forma fácil e intuitiva para la persona que este manipulando la herramienta, estableciendo así fecha y hora en la cual se registrará la venta, posteriormente se seleccionara el concepto de la compra, si es débito o crédito para su posterior registro la base de datos de CXC, ingreso de producto tanto por código o por nombre, visualización de las existencias del artículo de su precio unitario, ingreso de la cantidad a registrar y su sub total, en la parte inferior se establecerá el total de la compra permitiendo a la persona ingresar el dinero recibido y la herramienta procederá a calcular el valor a devolver dado sea el caso, y posteriormente su registro a la base de datos establecida por la herramienta, como se muestra en la Figura 7.

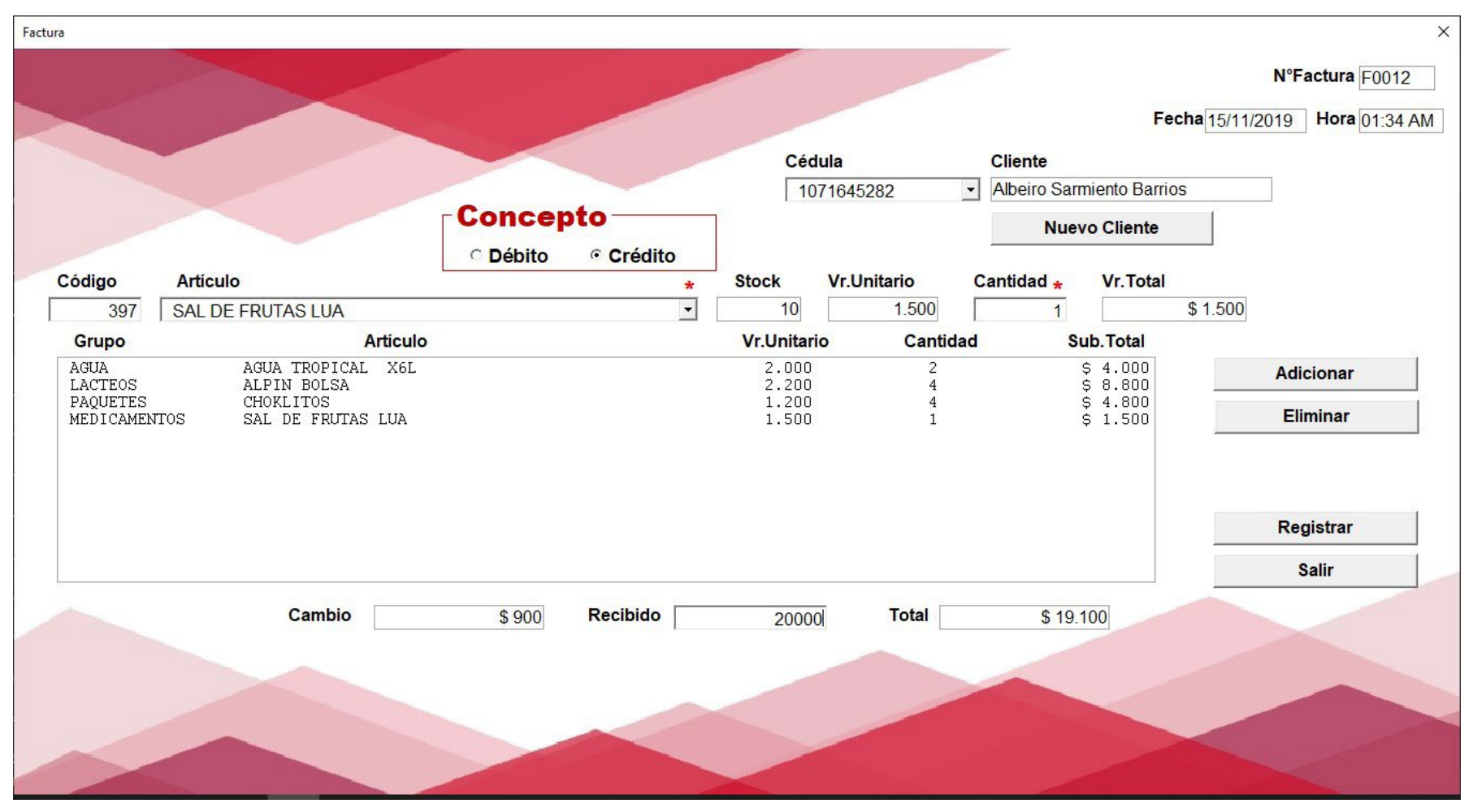

Figura 7. Registro de ventas y facturación.

Fuente: Elaboración propia a partir de VBA (2019).

\section{Consulta de facturas históricas, diarias, semanales y mensuales}

En la Figura 8 se evidencia como la herramienta totaliza por facturas diarias, semanales, mensuales y desde que se inicia la herramienta el histórico de la información, permite eliminar facturas de la base de datos, o consultar independientemente cada una. 


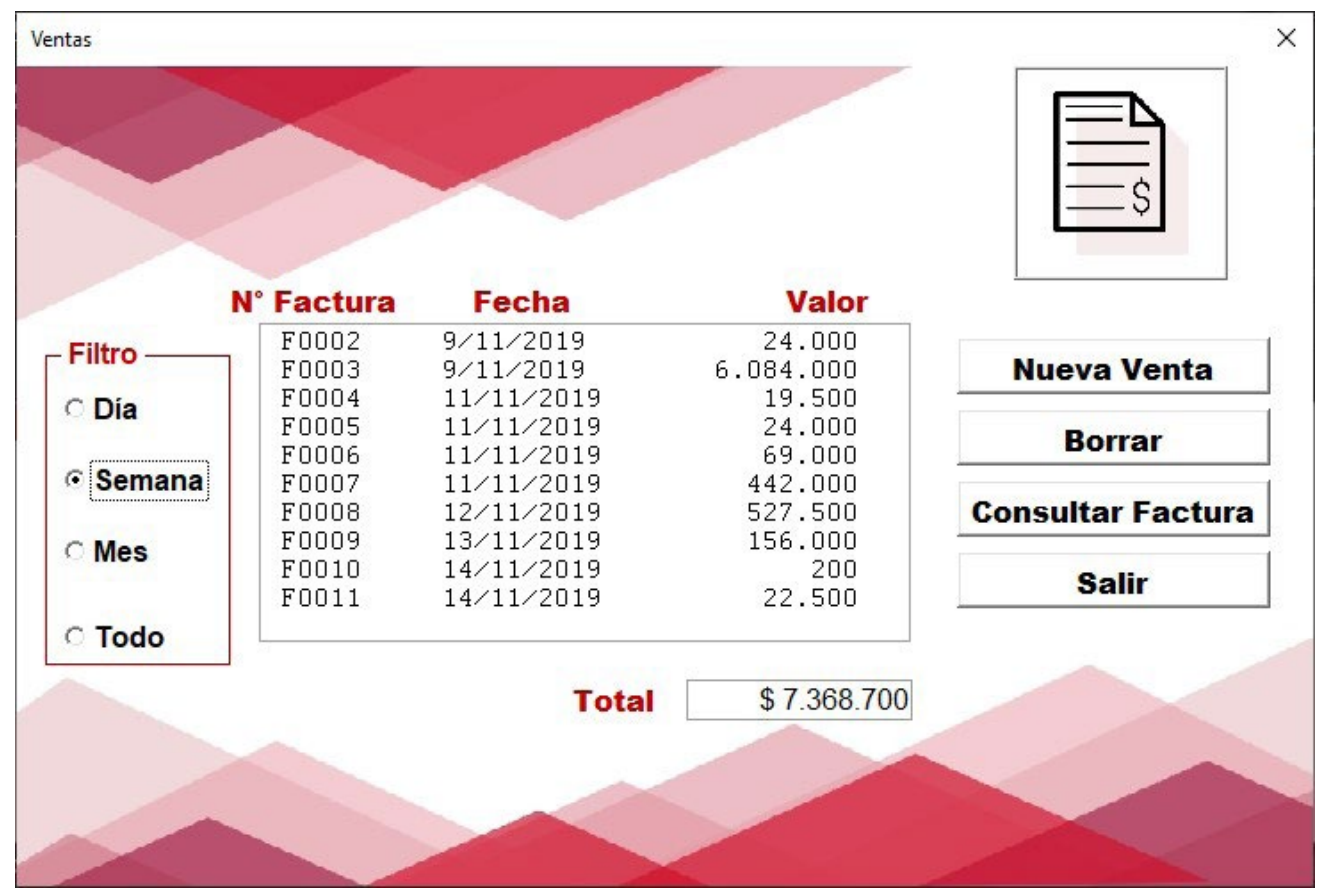

Figura 8. Totalización de facturas.

Fuente: Elaboración propia a partir de VBA (2019).

Consulta, ingreso y modificación de nuevos productos (existencias, entradas y salidas)

Consulta por código de producto, ingreso de nuevos y modificación de los ya ingresados por descripción, categoría, valor unitario, costo y existencias para su posterior registro en la base de datos, como se muestra en la Figura 9.

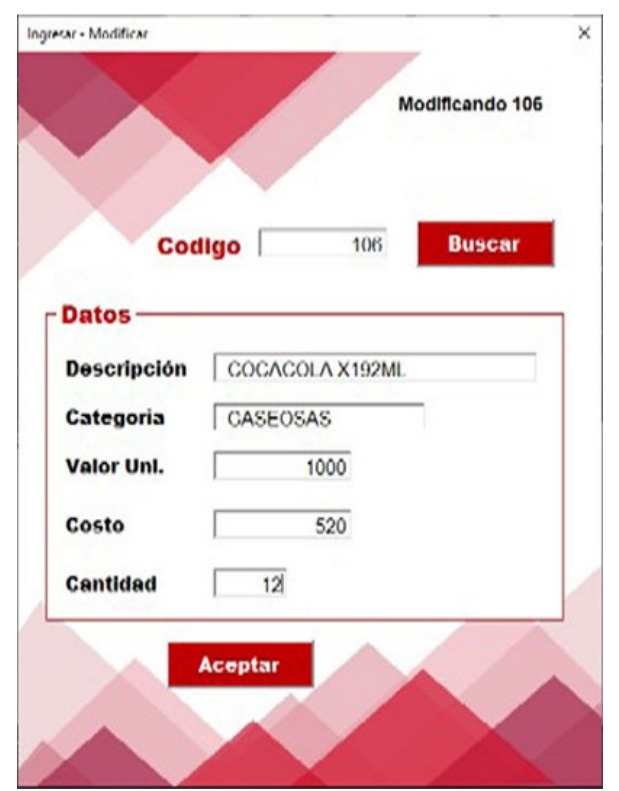

Figura 9. Consultas de inventario.

Fuente: Elaboración propia a partir de VBA (2019). 


\section{Consulta, ingreso y modificación de CXC}

En la Figura 10 se muestra cómo se realiza e Registro de nuevo cliente, en la parte de facturación al asignar el tipo de concepto de la venta sea el caso seleccionado el apartado de crédito se habilitará la selección del cliente responsable de la venta a crédito adquirida para su posterior almacenamiento y seguimiento por la herramienta.

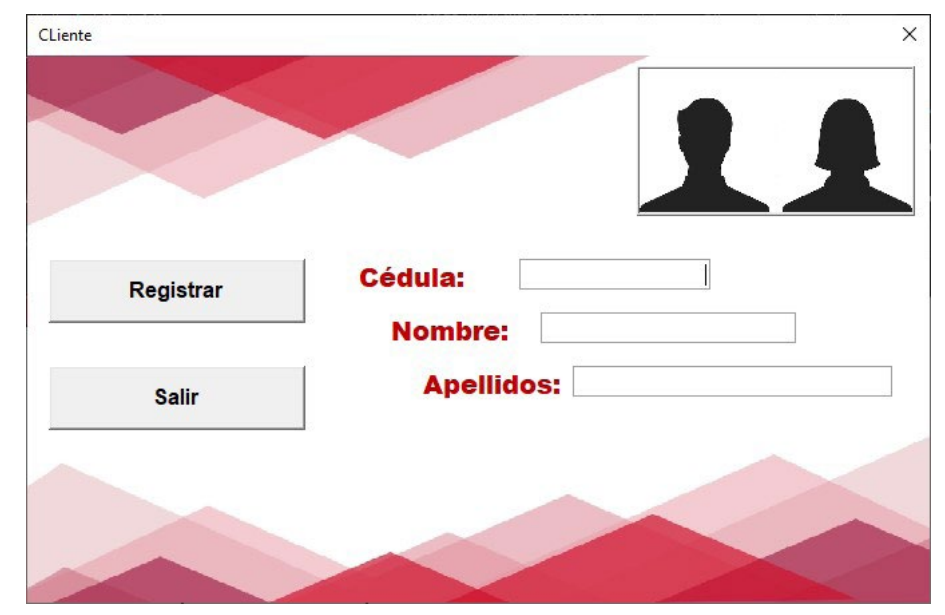

Figura 10. Consulta, ingreso y modificación de CXC Fuente. Elaboración propia a partir de VBA (2019).

\section{Consulta, ingreso y modificación de Gastos}

En la sección de gastos, se podrá visualizar, ingresar, borrar o modificar los gastos que la tienda tenga permitiendo así tener previo control sobre estos, llevando así un seguimiento claro de las alteraciones que estos pueden generar mes a mes, y teniendo así la información necesaria para la toma de decisiones del funcionamiento y operación de la tienda, como se muestra en la Figura 11.

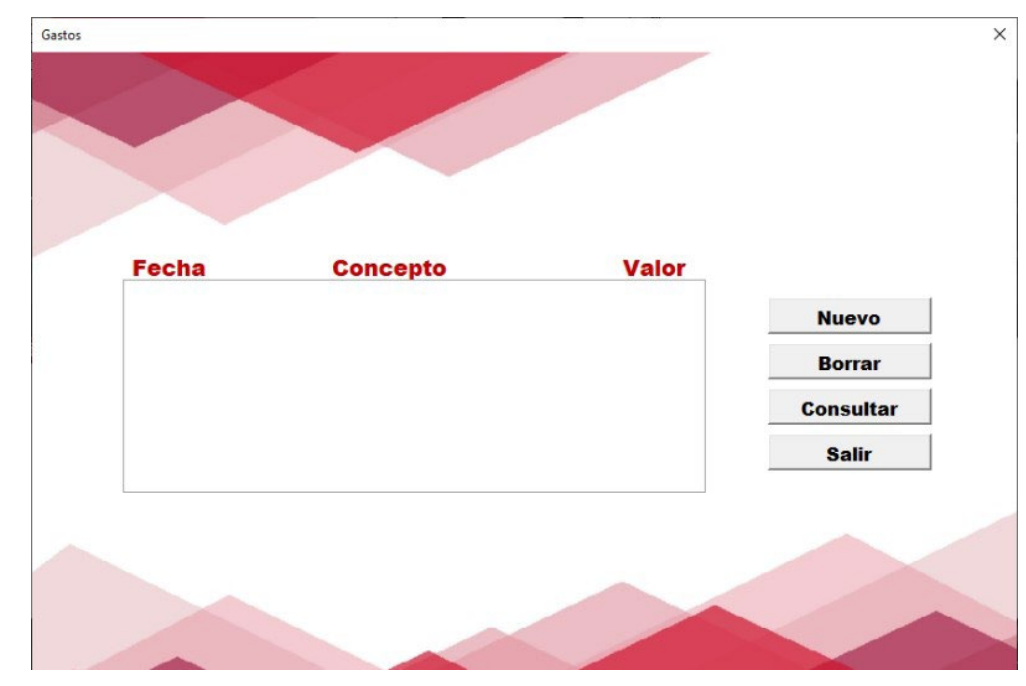

Figura 11. Consulta, ingreso y modificación de gastos Fuente. Elaboración propia a partir de VBA (2019). 


\section{Consulta, ingreso y modificación de Proveedores}

La herramienta permite registrar, consultar y modificar la base de datos de sus proveedores, esta base datos se encuentra enlazada con la facturación, y las compras, que permitirán visualizar el ingreso de mercancía por producto, y consultando los productos por proveedor (Figura 12).

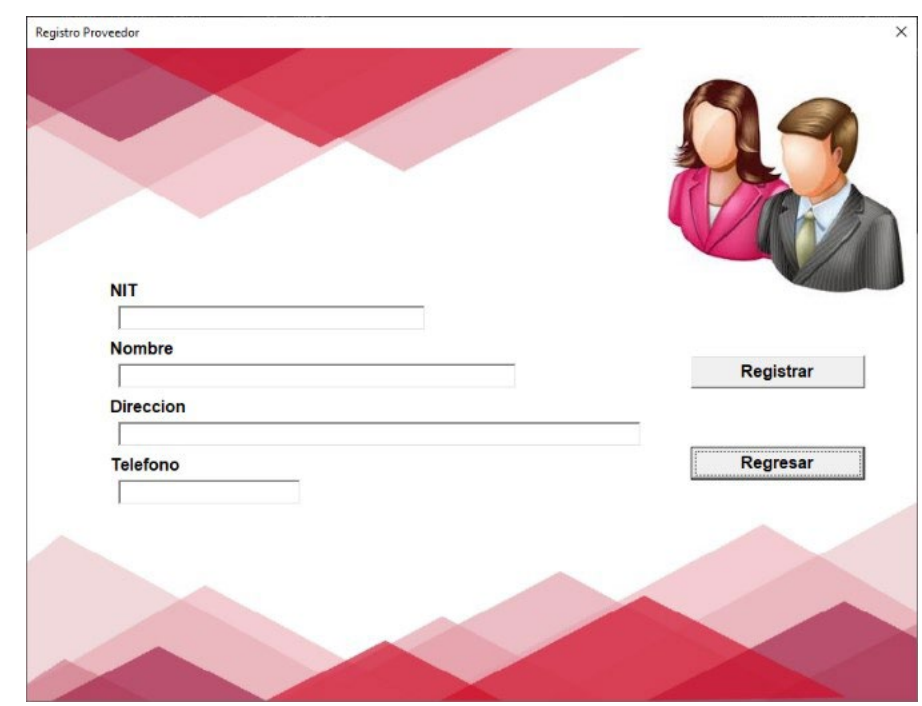

Figura 12. Consulta, ingreso y modificación de gastos. Fuente. Elaboración propia a partir de VBA (2019).

\section{Reportes}

Para la sección de reportes se establecerá como se muestra en la Figura 13, información fácil de entender con la cual el microempresario de barrio pueda tomar decisiones sobre su negocio, permitiendo así esta sección resumir información dentro de rango de fechas establecidas por la persona, que posteriormente este podrá filtrar por tipo de producto, su categoría, arrojando así su comportamiento de venta, su margen de contribución y la utilidad del periodo establecido, por otra parte, se espera implementar información gráficamente entendible sobre el comportamiento que estos productos tienen en el lapso de tiempo establecido.

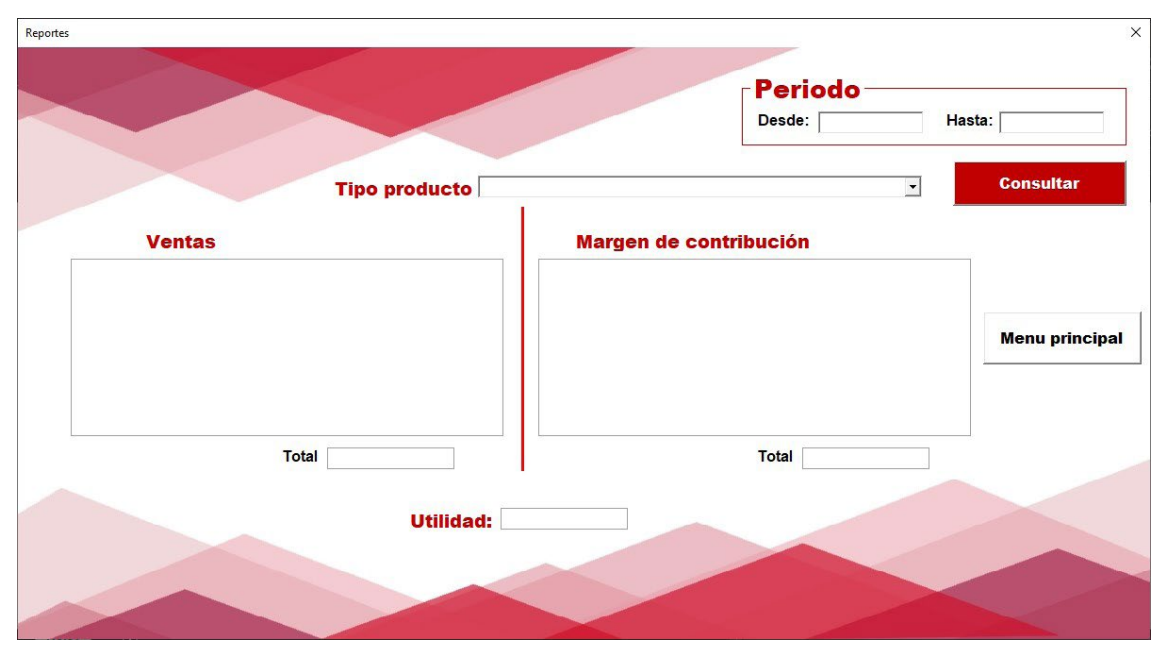

Figura 13. Reportes.

Fuente. Elaboración propia a partir de VBA (2019). 


\section{RESUltados}

\section{Arqueo Caja}

La validación toma un valor de caja inicial de $\$ 28.000$ COP (monedas y billetes) a la 9:15 A.M entre los cuales para el caso estudio demora un promedio de 180 segundos, como resultado de la validación del software arroja una disminución de tiempo en tan solo 1 segundo, 99.4\% menos que de la manera convencional (Tabla 2).

TABLA 2.

Optimización efectiva

\begin{tabular}{|c|c|c|c|c|c|c|}
\hline \multicolumn{3}{|c|}{ Total } & & & & \\
\hline Valor existente & $\$ 28.000$ & & \multicolumn{2}{|c|}{ *Segundos } & \multicolumn{2}{|l|}{ "Segundos } \\
\hline Efectivo & & & Antes & Después & Diferencia & $\%$ \\
\hline Conteo Tiempo & 180 & Segundos & 180 & 1 & 179 & 99,4 \\
\hline
\end{tabular}

Fuente: Semillero Economía Financiera (Semillero ECOFI, 2019).

\section{Ventas}

Se realizó una prueba de campo de 20 tomas de tiempo diferentes en un lapso de 1 hora, 10 bajo el esquema manual usado por la tienda caso de estudio y 10 implementando el software, las pruebas promedias entre tiempos de atención a los clientes, tiempo de despacho y tiempo de entrega de dinero (Tabla 3 y Figura 14).

TABLA 3.

Optimización ventas

\begin{tabular}{llllll}
\hline \multicolumn{1}{c}{ Validación } & Antes & Después & Diferencia & $\%$ \\
\hline 1 & 28 & 6 & 22 & 78 & \\
2 & 40 & 8 & 32 & 80 & \\
3 & 55 & 8 & 47 & 85 & \\
4 & 11 & 4 & 7 & 60 & \\
5 & 18 & 4 & 14 & 77 \\
6 & 15 & 4 & 11 & 73 \\
7 & 14 & 4 & 10 & 69 \\
8 & 17 & 5 & 12 & 73 \\
9 & 54 & 11 & 43 & 80 & \\
10 & 17 & 4 & & 74 & \\
& & & & & \\
Promedio & 27 & 6 & 21 & 78 \\
\hline
\end{tabular}

Fuente: Semillero ECOFI (2019). 
-ANTES QDESPUÉS

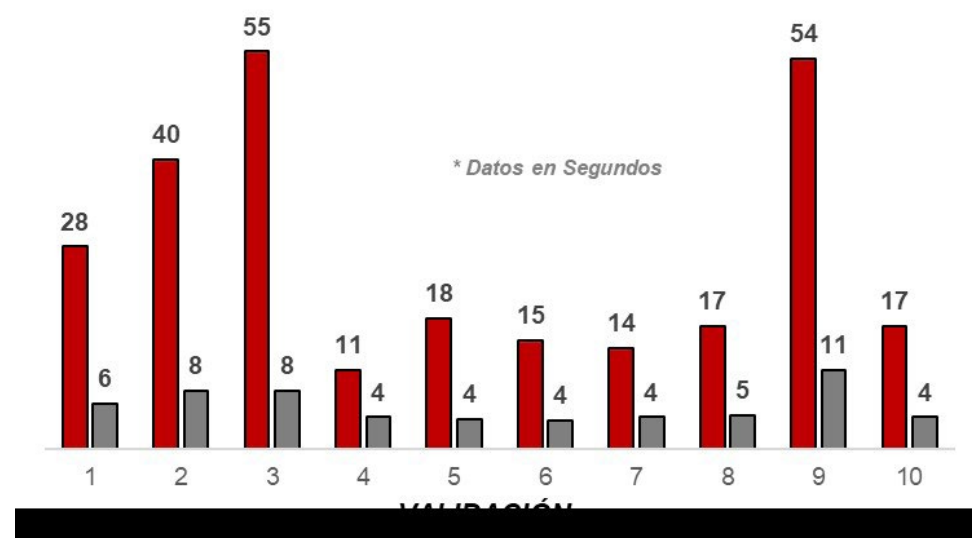

Figura 14. Optimización ventas.

Fuente: Semillero ECOFI (2019).

\section{Inventario}

A su vez implementando la herramienta uno de los procesos más tediosos para las tiendas consiste en el registro de nuevas unidades para su posterior venta, en promedio podían tardas casi 5 minutos o más dependiendo del producto que adquirían a sus proveedores, implementando la herramienta la compra y aumento de unidades la realiza en 1 minuto o menos, optimizando el proceso en un 93\% (Tabla 4 y Figura 15).

TABLA 4.

Optimización inventario.

Fuente: Semillero ECOFI (2019).

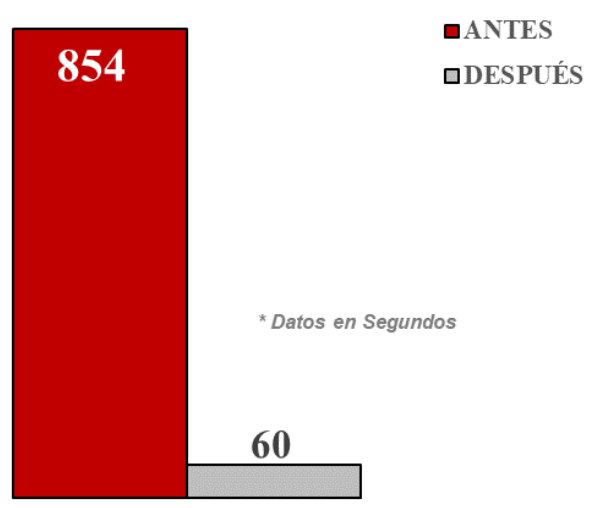

Figura 15. Optimización inventario.

Fuente: Semillero ECOFI (2019). 


\section{Cuentas por cobrar}

El seguimiento y totalización de las cuentas por cobrar que llevan las tiendas es mediante una metodología empírica y poco efectiva que lleva a que las tiendas no logren realizar una buena gestión de estas, pueden demorarse poco más de 2 minutos si su metodología está un poco gestionada, implementada la herramienta la gestión se mejora $84 \%$ permitiéndole a la tienda administrar de manera eficiente estas cuentas pendientes con sus clientes (Tabla 5).

TABLA 5.

Optimización Cuentas por cobrar.

\begin{tabular}{|c|c|c|}
\hline \multicolumn{3}{|c|}{ "Segundos } \\
\hline $\mathrm{CXC}$ & Totalización XCX & 65 \\
\hline & Seguimiento CXC & 120 \\
\hline
\end{tabular}

\begin{tabular}{ll}
\multicolumn{2}{l}{ "Segundos } \\
\hline Antes & Después \\
\hline $185 \quad 30$ & \\
\hline
\end{tabular}

\begin{tabular}{lr}
${ }^{*}$ Segundos & \\
\hline Diferencia & $\%$ \\
\hline 155 & 83,8 \\
\hline
\end{tabular}

Fuente: Semillero ECOFI (2019).

El contraste que se da en la gestión empírica y manual que normalmente se desarrolla en las tiendas de barrio contra la gestión realizada una vez se implementa la herramienta tecnológica es bastante positivo. Los indicadores de gestión son exponencialmente mejorados gracias a la sistematización de los procesos, además se reduce el tiempo diario en actividades que eran sumamente engorrosas para el tendero, las cuales no solo le restaban tiempo sino también le generaban riesgos como pérdida de información, pérdida de clientes y deterioro de sus productos.

Igualmente, la herramienta permite al tendero conocer al instante cual es la evolución de sus ventas, sus utilidades operativas y netas lo cual permite realizar toma de decisiones efectivas a la hora de controlar sus niveles de inventario, otorgar crédito y realizar pedidos.

De otro lado, le permite acceder a nuevas fuentes de financiación ya que obtiene de forma ordenada y sistematizada reportes que le muestran las posibilidades de asumir o no futuras obligaciones de acuerdo con el análisis y la evolución de los flujos de efectivo que tenga.

La innovación financiera representada en esta herramienta permite no solo mejorar los indicadores de gestión sino también los financieros ya que al estar netamente relacionados con la actividad y ligada a las operaciones de la cadena de valor, permite gestionar con mayor eficiencia los niveles adecuados de inventarios, estableciendo parámetros en el control de stock, devoluciones, perdidas por baja rotación lo cual aporta a la reducción de los días mostrados en rotación de inventarios.

A su vez, en cuanto a las cuentas por cobrar y pagar con el uso de la herramienta se controla por una parte los clientes a los que se les otorgo crédito y se puede iden- 
tificar los niveles adecuados de cupo por cliente. En cuanto a las cuentas por pagar permite no solo controlar los pagos sino también ser mucho más ágil la recepción de la mercancía y la solicitud de compra de esta.

\section{Conclusiones}

El análisis y buen manejo de la información financiera permite a los microempresarios en este caso del sector comercial, poder tomar decisiones eficientes de inversión y financiación lo cual facilita el desarrollo de estrategias de crecimiento bien sea a través de la expansión o la remodelación de sus activos fijos.

La implementación de la herramienta tecnológica reduce los tiempos de gestión y optimiza los procesos, lo cual genera eficiencia en la realización de las actividades operativas y de ventas. Permitiendo así poder potencializar la actividad comercial, mejorar el servicio al cliente y facilitar la relación con los proveedores.

Al optimizar la gestión del capital de trabajo a través del uso de la herramienta, se mejora la capacidad de negociación con clientes y proveedores permitiendo al tendero tomar decisiones cuando existan beneficios en compras y así mismo poder otorgar promociones y/o descuentos a los clientes lo cual dinamiza la actividad económica y genera reconocimiento en la zona.

La constante revisión de los procesos que se realizan al interior de la cadena de valor y en la medida que se generen nuevos indicadores de gestión que conlleven a la implementación de nuevos alcances para la herramienta continuaran fortaleciendo la gestión realizada por los tenderos y esto traerá beneficios en cuanto a los niveles de competitividad, sostenimiento y crecimiento en el mercado.

\section{RECOMENDACIONES}

La implementación de la herramienta de gestión de capital de trabajo en tiendas de mayor tamaño con el fin de verificar la agilidad con la que procesa y que soporte la capacidad de datos suministrados.

Realizar reportes periódicos con el fin de tomar decisiones estratégicas frente a la gestión comercial, de cobranza y la gestión de inventarios en los negocios del sector tendero.

\section{Reconocimientos y Agradecimientos}

El presente artículo es un producto resultado de la investigación efectuada durante el año 2019, en la segunda fase del eje de encadenamiento Productivo y Asociatividad Estratégica del Macroproyecto Institucional: Modelo Alternativo de Inclusión e Innovación Productivo (MAIIP), desarrollado por el Programa de Ingeniería Financiera de la Universidad Piloto de Colombia Seccional del Alto Magdalena. Esta investigación se integra a los resultados obtenidos para el año inmediatamente anterior dentro de la cadena de valor del sector TAT del municipio, a partir de una empresa caso de estudio, en el eslabón de distribución el cual contempla el sector tendero de Girardot. 


\section{REFERENCIAS}

CEPAL. (2016). Manual para el fortalecimiento de las cadenas de valor. México, D.F.: Fondo Internacional de Desarrollo Agrícola. Disponible en https://www. cepal.org/es/publicaciones/40662-manual-fortalecimiento-cadenas-valor

CEPAL. (2013). Manual para el fortalecimiento de las cadenas de valor. México, D.F.: Fondo Internacional de Desarrollo Agrícola.

Cámara de Comercio de Santa Rosa de Cabal. (2018). Caracterización Sector Tendero de Santa Rosa de Cabal. Año 2018. Santa Rosa de Cabal: Gobernación de Risaralda. Disponible en https://www.camarasantarosa.org/caracterizacionsector-tendero-de-santa-rosa-de-cabal-2018/

FENALCO. (2018). Informe económico y de gestión 2018. [Online]. Disponible en http://www.fenalco.com.co/informegestion2018

FENALCO. (2017). Informe económico y de gestión 2017. [Online]. Disponible en http://www.fenalco.com.co/informegestion2017

FENALCO. (2016). Informe económico y de gestión 2016. [Online]. Disponible en http://www.fenalco.com.co/informegestion 2016

FMI. (2019). El Directorio Ejecutivo del FMI Concluye la Consulta del Articulo IV con Colombia. [Comunicado de prensa NO. 19/132]. Disponible en https://www. imf.org/es/News/Articles/2019/05/01/pr19132-colombia-imf-executive-board-concludes-2019-article-iv-consultation-with-colombia

Gitman, L. \& Zutter, C. (2012). Principios de administración financiera. México, D.F.: Pearson.

Hernández, R., Fernández, C. \& Baptista, P. (2016). Metodología de la investigación. (6 ed.). México, D.F.: McGraw-Hill.

Kaplinsky, R. \& Morris, M. (2009). Un Manual para Investigación de Cadenas de Valor.

Lozano, R. (noviembre 19, 2017). Las tiendas reinan de lejos entre negocios de barrio. eltiempo.com. Disponible en https://www.eltiempo.com/economia/sectores/ las-tiendas-de-barrio-representan-la-mayoria-de-los-negocios-de-comercio-al-detal-152784

Microsoft VBA. (versión 2019). Manual Técnico Tienda VBA. [Online].

Páramo, D. (2012). Editorial. Tiendas de barrio en Colombia. Revista científica Pensamiento y Gestión, (32), vii-xi. Disponible en http://rcientificas.uninorte.edu. co/index.php/pensamiento/article/view/3982

Peña, R. P. \& Ortiz, A. (2014). Microfinanzas aplicadas a los municipios del Alto Magdalena y otras regiones. Revista de tecnología, 13(1), 87-101. Disponible en https://revistas.unbosque.edu.co/index.php/RevTec/article/view/1303

Porter, M. (2009). Estrategia competitiva. Madrid: Pirámide.

Semillero ECOFI. (2019). Informe Sector Tendero. Girardot: ECOFI.

Tapiero, J., Montaña, G. \& Sanchez, J. (2018). Estudio socieconómico en las tiendas de barrio del municipio de Girardot. [Trabajo de grado]. Corporación Universitaria Minuto de Dios, Girardot, Colombia. Disponible en http://hdl.handle. net/10656/6658 


\section{BIODATA}

Francia Elena Cruz Puentes es Economista de la Universidad Santo Tomas (Colombia). Especialista en Gerencia y Administración Financiera de la Universidad Piloto de Colombia. Especialista en innovación y pedagogía universitaria de la Universidad Piloto de Colombia. Magister en educación de la Universidad del Tolima (Colombia). Con interés de investigación en economía, innovación financiera, modelos económicos y estocásticos. Investigador de la Facultad de Ingeniería de la Universidad Piloto de Colombia S.A.M. https://orcid.org/0000-0002-7883-5820

Andrés Felipe Atehortua Leal es Ingeniero financiero de la Universidad Piloto S.A.M. (Colombia) Especialista En Gerencia Comercial de la Universidad de la Sabana (Colombia). Con interés de investigación en gestión de capital, estrategias financieras, mercado de capitales, inversiones y modelos de negocio. Investigador de la Facultad de Ingeniería de la Universidad Piloto de Colombia S.A.M. https:/orcid. org/0000-0003-0210-5618

Gabriel Enrique Gutiérrez Parra es Ingeniero de sistemas de la Universidad Nacional (Colombia). Especialista en Finanzas de la Universidad del Externado de Colombia. Especialista en Matemática aplicada de la Universidad Sergio Arboleda (Colombia) y Maestría en Física de la Universidad Nacional. Con interés de investigación en aplicación de software sobre herramientas financieras, matemática financiera y finanzas cuantitativas con python. Investigador de la Facultad de Ingeniería de la Universidad Piloto de Colombia S.A.M. https:/orcid.org/0000-0001-5000-9714 